\title{
A filosofia de Hegel à luZ da TeORIa do ROMANCE DO JOVEM LUCKÁCS
}

\author{
Antonio Vieira da Silva Filho'
}

Resumo: A partir da Teoria do romance do jovem Lukács, o artigo desenvolve uma discussão com a filosofia de Hegel, no que concerne, de um lado, à herança da dialética histórica hegeliana, presente na Teoria do romance, e, de outro lado, ao distanciamento do autor húngaro das conclusóes de Hegel sobre a unidade efetiva entre indivíduo e Estado moderno. A herança hegeliana na obra de Lukács é definidora na sua compreensão da relação imanente e necessária entre forma artística e conteúdo histórico. Para Hegel, a modernidade e a instituiçấo do Estado aparecem como o mais alto índice da liberdade do homem, na história; para Lukács, ao contrário, a modernidade se apresenta como o coroamento da dissonância entre indivíduo e as suas estruturas sociais, processo de separação que se inicia quando o mundo da epopeia é suplantado pela Grécia estatal da tragédia e da filosofia.

Palavras-Chave: Teoria do romance. Lukács. Espírito. Estado. Hegel.

\section{INTRODUÇÃo}

Aqui está a [minha] Rosa, aqui vamos dançar Filosofia do direito.

Hegel

A assunção de Lukács da categoria hegeliana de espírito, para pensar a história, parece ter fundamento sólido na exposiçáo do autor da Teoria do romance, em particular na tematização das relaçóes imanentes entre teoria dos

${ }_{1}^{1}$ Professor de Filosofia do Instituto de Humanidades e Letras e do Mestrado Interdisciplinar em Humanidades da Universidade da Integração Internacional da Lusofonia Afro-brasileira (UNILAB), Redenção, CE - Brasil. E-mail: antoniovieira@unilab.edu.br

Mestre e Doutor pela Universidade de São Paulo (USP) e autor do livro Poesia e prosa: arte e filosofia na estética de Hegel.

http://dx.doi.org/10.1590/0101-3173.2018.v41n4.05.p75 
gêneros e teoria da história, isto é, na relação apresentada entre as formas da grande épica e a "marcha do espírito na história." (LUKÁCS, 2000, p. 27). Se o conceito de espírito liga os dois autores, é certo que ele também os separa. Essa separação se dá na reconciliação do indivíduo com as estruturas da vida social, pensada por Hegel, o que permite ao jovem Lukács, partindo da afirmação da "existência da dissonância" como verdade do mundo moderno, opor a perspectiva crítica da Teoria do romance a uma filosofia da história hegeliana, cujo termo o Estado moderno realiza. A separação é visível, no que concerne às conclusóes de Lukács quanto ao Estado moderno e as suas estruturas sociais. A divergência se desdobra igualmente quanto ao sentido imanente do desenvolvimento histórico que, em Hegel, conduz até o Estado moderno como ápice da trajetória histórica do espírito e que, na Teoria do romance, essa mesma modernidade se configura como o ápice da "objetivação histórico-filosófica da alienação do homem em relação às suas estruturas.” (LUKÁCS, 2000, p. 65).

Lukács assinala a relação entre as duas grandes formas da épica como desenvolvimento imanente à forma social, afirmação já pontuada quando o autor escreve que "epopeia e romance, ambas as objetivações da grande épica, não diferem pelas intençóes configuradoras, mas pelos dados histórico-filosóficos com que se deparam para a configuração.” (LUKÁCS, 2000, p. 55). Isso já apresenta certa reelaboração da dialética entre indivíduo e Estado apresentada por Hegel, elaboração que, em última análise, diz respeito à crítica de Lukács à reconciliação do indivíduo moderno no Estado. A imanência da forma à experiência histórico-social é, em Hegel, inseparável da mediação do Estado, também chamado pelo filósofo alemão de mundo da prosa.

O desdobramento imanente das formas da épica na Teoria do romance indica a relação, explicitada sob os conceitos de sentido e de vida, entre a alma e a sua experiência no mundo, em cada configuração histórica particular. $\mathrm{O}$ movimento descrito parte da relação de imanência imediata do sentido à vida, na epopeia, passa pela fase germinal da cisão dessa imanência, realizada na experiência estatal grega da pólis ateniense, cisão que se expóe na forma da tragédia e da filosofia grega, para se efetivar no mundo moderno, sob a expressão do romance, que recria artisticamente a unidade perdida na cisáo que opóe essência e vida (LUKÁCS, 2000, p. 32-33). Lukács pensa esse processo como uma gradativa separação entre a vida e o sentido, cujo índice é dado pela alienação do homem em relação às suas estruturas sociais.

A lógica subjacente a essa compreensão da alienação gradativa do homem em relação às suas estruturas é a mesma lógica hegeliana que explica o es- 
pírito e seu processo de objetivação. Trata-se de entender como a problemática hegeliana da história, concebida a partir do desdobramento especulativo sujeito-objeto, apresenta-se para o autor húngaro. A mesma premissa hegeliana da relação de objetivação do sujeito é exposta por Lukács, chegando, entretanto, a conclusóes invertidas, no tocante à modernidade e às suas estruturas sociais.

\section{Hegel: a PROSA DA HISTÓRIA E A RECONCILIAÇÃo dA PARTE COM O TODO}

O estado do mundo prosaico é tomado por Hegel como aquele que rompe com o estado do mundo heroico, acolhido pela configuração artística da epopeia. Para ele, a prosa da vida tem início quando aquele estado, reclamado pelo ideal de arte, tem seu fim. Afirma Hegel (2004, p. 37):

O histórico propriamente dito "segundo o objeto e a coisa, toma o seu início apenas ali onde termina a época heroica - que deve ser vindicada originariamente à poesia e à arte: ali, portanto, onde a determinidade e a prosa da vida está dada tanto nos estados efetivos quanto na concepção e na exposição dos mesmos.

O mundo prosaico e o seu modo de representação, a prosa, configuram-se e se apresentam exclusivamente no palco propriamente histórico. A história é, para Hegel, o cenário dos acontecimentos e feitos humanos, fatos e feitos ocorridos no seio da vida social, mediada estatalmente. A história começa quando começa a vida no interior dos Estados e, desse modo, ele caracteriza a história como sendo a história dos Estados (HEGEL, 1989, p. 100 ss).

A prosa surge determinada pela história. A história surge determinada pela subjetividade prosaica e, como se trata de uma relação de mútua determinação, a subjetividade prosaica surge com a objetividade do mundo prosaico. A consciência de si enquanto livre é o fator que permite compreender a história como o lugar da objetividade dessa consciência. A história, tal como a concebe Hegel, é o autodesenvolvimento do espírito no mundo, com a tarefa de conhecer a si mesmo enquanto espírito livre, ou seja, é o desenrolar do espírito universal no tempo histórico com a finalidade de atingir o mais alto grau da liberdade humana. O espírito universal é, em Hegel, a própria razão, provida de vontade, cuja determinação fundamental é aquilo que conhecemos com o nome de liberdade. A história é compreendida como progresso da liberdade humana em vista de uma perfectibilidade mundana do espírito (HEGEL, 1989, p. 59 ss). O estado reivindicado pela epopeia aparece, ao 
contrário do estado histórico, como um mundo desprovido de liberdade, ou melhor, tal liberdade é pensada por Hegel como aparecendo apenas de maneira indeterminada.

O conceito de espírito universal mediado pelo espírito do povo "permite estreitar a relaçáa" entre a particularidade e a universalidade, ou seja, entre o povo e o Estado (a ponto de haver, às vezes, uma tendência à identidade entre ambos), pois o "espírito do povo" é a consciência que o povo tem da sua constituição política, enquanto ela penetra e perpassa todas as relaçôes desse povo, os costumes e a consciência dos indivíduos; é nessa consciência e no sentimento do seu direito que não só reside a liberdade subjetiva de um povo, mas a própria realidade efetiva da constituição do Estado. De um lado, a totalidade da vida grega está em direta consonância com a liberdade individual; de outro, a liberdade dos indivíduos apenas se torna efetiva posta universalmente, de modo imediato, pelo Estado.

Como se trata de mostrar a compreensão da história, por Lukács, em sua relação com o conceito de espírito hegeliano, discutiremos, dessa forma, a concepção de espírito em Hegel, em conexão direta com a matéria da história por excelência, a saber, a relação entre os conceitos de espírito do povo e o Estado. Essa relação nos ajuda a explicar o que significa, na Teoria do romance, a afirmação de um "espírito grego".

A dialética entre espírito universal e espírito do povo determina, para Hegel, o movimento progressivo da Ideia na realização da liberdade. Hegel define o espírito, inicialmente, de maneira abstrata, como espírito universal do mundo. $\mathrm{O}$ espírito necessita de realização no interior do espírito de um povo que manifeste a concordância com a finalidade do espírito universal, a qual é determinada pelo desenvolvimento da liberdade universal no interior de um Estado. O espírito do povo grego, desse modo, em certa época da história universal, estava em perfeita concordância com a determinação do espírito universal. $\mathrm{O}$ espírito de um povo começa a ruir, quando não mais está em concordância com o espírito universal. Assim, o princípio universal que guiava todos os homens no interior do Estado é questionado, é repartido e o sujeito volta-se sobre si e sobre a satisfação dos seus próprios interesses. Há uma cisão entre o universal do Estado e o princípio subjetivo, todavia, o espírito universal é a Ideia, o guardião da liberdade. A derrocada de um princípio particular, do Estado ateniense, por exemplo, dá lugar a uma forma mais determinada do espírito universal. O espírito do povo aparece em sua verdade na universalidade do Estado e, assim, a consciência moral, o direito, a religião 
e demais esferas da vida do homem, ou seja, "a cultura de uma naçâo [...] está encerrada na realidade concreta do Estado, [que] é o espírito mesmo do povo.” (HEGEL, 1989, p. 103).

Essa estreita relação entre o espírito de um povo e o Estado é a mesma conexão efetuada por Hegel entre o espírito do povo e o espírito universal. Um determinado povo só é efetivamente livre no interior do Estado, na medida em que as particularidades individuais são postas em relação com o universal, pois as liberdades individuais apartadas do todo permaneceriam apenas uma liberdade abstrata, e a relação do particular com o universal é que faz com que as partes convirjam para a finalidade do todo. Da mesma maneira, vemos o espírito do povo como mediação na relação com o espírito universal, porque o povo que se apresenta como parte da história universal é justamente aquele no qual a liberdade está em, por assim dizer, imanente consonância com a finalidade do espírito universal. Essa finalidade não é atingida no começo, mas, ao contrário, para se atingir o telos, é necessário um trabalho paciente de milênios. A história começa com o povo persa: para Hegel, "os persas são o primeiro povo histórico.” (HEGEL, 1989, p. 323). Mas se trata apenas do começo, porque a determinação fundamental do espírito universal é se autoconceber como atividade e autodesenvolvimento - categorias que conotam uma ideia de progresso - com a finalidade de autoconhecimento, da liberdade em seu mais alto grau (HEGEL, 1989, p. 75). As relaçôes da vida prosaica se desenvolvem até atingir seu mais alto grau de liberdade. Tanto a história como as relaçóes prosaicas, as quais aparecem com o surgimento daquela, caminham progressivamente para um desenvolvimento que é o desenvolvimento da consciência de si como livre, expressa no Estado.

O conceito hegeliano se autoproduz e se desenvolve no mundo, produzindo assim em cada época uma determinação fundamental. O filósofo da história, nesse sentido, apreende a racionalidade do mundo e pode compreender, a partir do seu presente, que a determinação fundamental do conceito no espírito do povo grego, por exemplo, manifesta-se artisticamente, já que, na Grécia, o artístico perpassa toda a vida efetiva daquele povo, desde a mais simples atividade do espírito até a mais desenvolvida, desde a maneira de se portar do cidadão na assembleia até a constituição do Estado. A autoprodução e o autodesenvolvimento do espírito universal é a manifestação da razão no mundo. A objetivação do espírito universal no negativo de si é a exteriorização da Ideia no espírito de um determinado povo. 
Trata-se, para Hegel, de pensar o processo histórico como progresso do espírito rumo à consumação da unidade mediada entre sujeito e objeto, realizada no (e através do) Estado moderno. Isso significa que a objetivação aparece como confirmação do espírito, como autoposição do sujeito. Não se trata para Hegel de um idealismo subjetivo, mas o movimento é dialético, na medida em que, para ele, a subjetividade racional se realiza na objetividade igualmente racional e somente nela encontra a sua liberdade. A identidade não é entre o arbítrio da subjetividade - das paixôes e sentimentos - e o objeto, mas entre a objetividade e o conteúdo racional subjetivo.

Para a filosofia especulativa, a dialética sujeito-objeto está alicerçada na determinidade do objeto como imanente ao sujeito substancial. O sujeito aqui não é determinado pela vontade individual, pela subjetividade das paixôes e sentimentos particulares, limitados - embora tenha papel ativo na realizaçáo da liberdade -, porém, pela "vontade universal e essencial" que se efetiva na objetividade igualmente substancial (HEGEL, 1989, p. 101). Essa vontade universal e essencial é a liberdade "que sabe, crê e quer o universal [o Estado]." (HEGEL, 1989, p. 100). O processo não é de cópula entre sujeito e predicado, mas, em função do sujeito substancial, é internamente desenvolvido um objeto igualmente substancial. Esse sujeito se desenvolve, por meio desse processo de objetivaçáo, como outro/mesmo sujeito, agora mais determinado e mais idêntico com a verdadeira substância, a qual, a partir de si, desenvolve um objeto igualmente mais determinado, contudo, que permanece substancialmente idêntico ao sujeito. Esta é a dialética lógico-histórica, que pode ser traduzida pela dialética forma-conteúdo. A dialética de identidade e não-identidade ou de unidade e suspensão desta por um conteúdo histórico e uma forma de exposição mais desenvolvida, assume uma dimensão tal que a filosofia hegeliana anuncia a unidade entre conteúdo histórico moderno e a forma especulativa de apreensão e exposição da totalidade desse conteúdo.

O todo é, assim, apresentado no "final" do processo, embora seja também a sua condição, na medida em que o objeto da própria filosofia especulativa - a experiência histórica moderna - é o ponto de partida para essa exposição lógica. É por isso que a modernidade e seu modo de exposição e apreensão da realidade, a filosofia, aparecem, para Hegel, como a consumação e paradigma da unidade entre sujeito e objeto ou da unidade entre forma e conteúdo. $\mathrm{Na}$ dialética entre o todo e a parte, Hegel não concebe como simples separação a relação entre o todo e a parte. Esta é, assim, o todo ainda indeterminado, assim como o todo é a suspensão da unilateralidade das partes 
numa totalidade verdadeira. A "unidade substancial", termo usado por Hegel na Filosofia do direito, ou a suspensão da separação entre o todo e as partes, é efetivada, conforme Hegel, pela liberdade ética do Estado moderno, concebido "como realidade efetiva da vontade substancial, realidade efetiva que ele tem na autoconsciência particular erguida à universalidade do Estado [...]. Esta unidade substancial é auto-fim absoluto, imoto, no qual a liberdade chega ao seu supremo direito.” (HEGEL, 1998, \$ 258).

\section{O JOVEM LUKÁCS EM DIÁlOGO COM A FILOSOFIA HEGELIANA: A SEPARAÇÁO ENTRE} A ALMA E AS ESTRUTURAS SOCIAIS

Para o autor húngaro, ao contrário de Hegel, trata-se de pensar o processo histórico de objetivação a partir da gradativa separação entre sujeito e objeto, cujo paradigma extremo a época moderna realiza. Aquilo que é visto por Hegel como confirmação da subjetividade reconciliada no Estado é compreendido por Lukács como alienação do sujeito em relação às estruturas sociais objetivas. No livro As formas e a vida: estética e ética no jovem Lukács (1910-1918), Machado cita a carta do autor húngaro ao amigo Paul Ernst, na qual discute, nos seguintes termos, a separação do sujeito em relaçáo ao objeto, na configuração social moderna:

A natureza das leis e a natureza dos estados de ânimo sáo provenientes do mesmo locus da alma: pressupóem elas a impossibilidade de uma substância consumada e significativa, a impossibilidade de o sujeito constitutivo encontrar um objeto constitutivo adequado. (LUKÁCS apud MACHADO, 2004, p. 63).

Nessa carta, escrita na mesma época da Teoria do romance, a problemática da cisão entre as estruturas objetivas e o sujeito constitutivo é traduzida em termos de uma relação entre o todo e a parte. Ernst afirma que o Estado é parte do todo. Com isso concorda Lukács, todavia, discorda da conclusão de Ernst, para quem o Estado é parte da alma. Tal discordância parece assumir uma dimensão epistêmico-metafísica na explicação da relação do todo com a parte e/ou da relaçáo do sujeito com o objeto. Após declarar que náo concorda com a concepçáo de Ernst sobre a participação do Estado na alma, Lukács elabora a questấo da seguinte maneira:

Tudo que está de qualquer modo em relação conosco é uma parte de nós mesmos (inclusive o objeto da matemática), mas esse todo que cria esses 
objetos (no sentido da função sintética da razão) traz em si problemas insolúveis, é um conceito metodológico abstrato, válida em âmbito das esferas metodológicas. O falso consiste, portanto, em transformar esse todo em alma, por meio do qual cada substanciação do sujeito significa um tornar-se substancial do objeto correspondente. (LUKÁCS apud MACHADO, 2004, p. 65).

Essa citação apresenta importantes desdobramentos. Ela deve ser entendida a partir do que nela aponta para uma discussão com a filosofia hegeliana. Assim, no último período da citação, Lukács recusa a objetivação moderna do sujeito, enquanto expressão, na realidade, de uma substanciação do objeto, do todo. Em As formas e a vida, Machado salienta que o problema tem conexão com Hegel, ao apresentá-lo no contexto no qual pretende esclarecer a oposição de Lukács ao espírito objetivo hegeliano. Trata-se da recusa de identificar o objeto como autodesdobramento do sujeito. Como um desdobramento dessa divergência, a citação indica a assunção, por Lukács, da separação entre a alma e o todo. O todo é apresentado como uma unidade formal, contraposto à realidade da alma, concebida como particular/individual, pois tal unidade é construída apenas de modo artificial e válido do ponto de vista metodológico. Essa separação entre alma e todo, na modernidade, evidencia dois elementos ou duas instâncias diferentes, porém, solidárias, que se referem, respectivamente, ao conteúdo e à forma do problema.

Do lado do conteúdo, essa oposição de Lukács à objetivação moderna manifesta a sua crítica ao caráter fragmentário das relaçóes da sociedade civil burguesa, recusa que tem como índice a separação entre o homem e o resultado de suas açôes. Tal caráter fragmentário é também apontado por Hegel quanto a essa esfera, mas, nele, suspenso na unidade do Estado. Ora, uma vez que Lukács discorda do processo por meio do qual Hegel eleva a vontade imediata à vontade individual racional - a sua mediaçáo pelo Estado -, a alma e o todo, desse modo, só poderão aparecer, para o autor húngaro, como apartadas, porque a mediação que os unifica em Hegel - a vontade individual como racionalidade da vontade subjetiva - não se apresenta como válida, pois ela pressupóe o Estado. O todo, nessa perspectiva, só pode ser visto como uma objetivação estranha, hostil ao sujeito, em razão da qual a totalidade é apresentada como formal. Entretanto, é preciso apontar que, contra Hegel, o que Lukács retoma é uma importante determinação da exposição do próprio Hegel acerca da modernidade: o caráter abstrato-formal da unidade e universalidade exposta na esfera da sociedade civil burguesa (HEGEL, 2000, \$187), 
caráter que é associado por Lukács à verdade ainda não superada dessa experiência, na medida em que ele atribui também ao Estado essa formalidade, a qual, em Hegel, apenas se refere à sociedade civil burguesa.

Do lado da forma, essa recusa à mediação estatal encontrada no âmbito do conteúdo deve se expor, segundo a objeção de Lukács à mediação do Estado, numa forma que expresse essa separação entre alma e todo. A assunção na Teoria do romance do método das ciências do espírito e muito particularmente da noção weberiana dos tipos ideais como "construtos", isto é, como abstraçôes para pensar a realidade, que separam forma e conteúdo, parece explicitar certa adequação dessa forma abstrata à abstração real da moderna social civil burguesa. É isso o que parece significar a assertiva de Lukács na carta a Ernst, na qual ele assevera que o todo, construído a partir da "função sintética da razão traz em si problemas insolúveis, é um conceito metodológico abstrato, válid(o) em âmbito das esferas metodológicas." (LUKÁCS apud MACHADO, 2004, p. 65). Isso não significa, contudo, uma adesão de Lukács à fragmentação moderna, mas apenas parece apontar para a necessidade de apresentar, na fragmentação da própria forma, a quebra da visão unitária e reconciliada alcançada na exposição hegeliana, a qual explicita a pretensão de que a unidade da forma do conceito é a expressáo da unidade efetiva no mundo.

A separação entre a forma e o conteúdo exige, ao mesmo tempo, a sua unidade ou justaposição, na medida em que unifica esses dois lados imediatamente, a cada uso concreto da forma. Esse procedimento é abordado por Lukács por meio da retomada do conceito kantiano de "função sintética", que é mediada pelas ciências do espírito. Ele parece querer denunciar que somente através de um procedimento metodológico abstrato é possível realizar a unidade entre o todo e a parte, entre a alma e as suas estruturas sociais. É por isso que essa assertiva se conclui na relação polêmica com a substanciaçáo da objetivação moderna, as qual atinge a pretensão hegeliana relativa ao todo, pois esta afirma, para além da validade puramente metodológica, uma unidade ontológica entre sujeito e objeto. Essa unidade, para Lukács, vai muito além da experiência da própria "alma" moderna, que, antes, caracteriza-se pela cisão em relação ao mundo.

Em Hegel, o conceito de espírito é inseparável de sua configuração objetiva, o Estado. Não obstante o distanciamento de Lukács em relação a essa posição de Hegel, segundo a qual o Estado é concebido positivamente, o autor húngaro parece também assumir, sob outras condições, determinaçóes centrais ao conceito de espírito do filósofo da história. Na discussão desse 
conceito, as relaçóes do autor da Teoria do romance com o círculo de Weber parecem assumir o seu lugar como um contraponto à dialética especulativa. ${ }^{2}$

Uma das maiores características da reflexão weberiana consiste em impugnar a validade da pretensão filosófica hegeliana em atribuir um sentido unitário ao desenvolvimento do espírito. Para Weber, as açóes sociais não podem ser conhecidas em funçáo da pressuposição da totalidade. Um fenômeno social, destacado da realidade pelo cientista, apresenta uma infinidade de causas, de finalidades distintas, de conexóes internas com os outros fenômenos e uma variedade infinita de determinaçóes. O cientista, para conhecê-los, necessita de pressupostos conceituais estabelecidos. A pretensão da compreensão de totalidade está associada, conforme pensa Weber, à "interpretação" dos "diferentes elementos da vida cultural" a partir de um único fator, a sua redução a ele. Weber critica na ocasião o "materialismo histórico". Este, para Weber, possui "a necessidade dogmática" de explicar as causas, as relaçôes e conexóes internas entre os vários elementos distintos da vida, com base em um único fator: o econômico. Ora, para Weber, o fator econômico é um fator, dentre vários outros, da vida cultural (WEBER, 1997, p. 84-88). A separação das esferas da vida espiritual, focalizada pelo sociólogo alemão, visa a apresentar a descontinuidade entre as diferentes esferas na produção do espírito. A filosofia hegeliana, que inspira o método materialista criticado por Weber, pensa a totalidade da experiência humana a partir do conceito de espírito, que unifica, possibilitando a conciliação das partes no todo.

Na discussão sobre o conceito de alienação do jovem Lukács na Teoria do romance, Arato e Breines asseguram que este entende o processo de alienação em termos de "uma função da produtividade do espírito." (ARATO; BREINES, 1986, p. 110). Esse elemento apontado por Breines e Arato nos leva por um caminho que coaduna Lukács e Hegel na mesma compreensão, qual seja, a de pensar a história em vista das categorias do mundo social, daquilo que em Hegel caracteriza o conceito de espírito.

Nossa hipótese é a de que o conceito de espírito que sustenta a afirmação de Arato e Breines, segundo a qual Lukács concebe a alienação a partir da "produtividade do espírito", apenas pode ser corretamente explicitado, quando consideramos sua relação contraditória com a concepção hegeliana

2 O autor da Teoria do Romance, em seu Prefácio de 1962, descreve da seguinte forma a sua adesão juvenil às ciências do espírito, mais especificamente Simmel, Dilthey e Weber: "o autor da Teoria do romance possuía uma concepção de mundo voltada a uma fusão de ética de 'esquerda' e epistemologia de 'direita'." LUKÁCS, 2000, p. 17). 
desse conceito. Tal relação contraditória se explicita pela assunção positiva da unidade entre forma literária e conteúdo da experiência histórica, que demarca as épocas históricas como "totalidades" de sentido. Essa unidade, em Lukács, entretanto, não é compreendida pela mediação positiva do Estado, mas pela negatividade dessa mediação, isto é, tanto mais separadas são as relaçóes entre alma e todo quanto mais se consolida a separação caracterizada pelo Estado em relação à alma. Essa negatividade é o que sustenta aquele caráter apenas formal da unidade, que, não por acaso, tem parentesco com a função crítica, sintética, em Kant. Na medida em que é a alma, em sua subjetividade, que fornece o critério de relaçáo com o sentido, ainda que tal critério seja referido à objetividade, ele é referido a esta negativamente. É por isso que, se Lukács reconhece as "totalidades" históricas particulares - reconhecimento que em Hegel só é possível em razão do critério da mediação objetiva do Estado -, a sua recusa em reconhecer o valor positivo dessa mediação faz com que o Estado apareça, também para ele, como critério das relaçóes entre a alma e o todo, embora tal critério seja, aqui, negativo.

Assim, a crítica a um desenvolvimento progressivo do espírito, a partir da qual Lukács pensará as relaçóes entre objetividade e subjetividade tem, como marco, a sua oposiçáa ao Estado. O conceito de espírito, utilizado por Lukács nas várias ocasióes da Teoria do romance, postula uma identidade moral, jurídica, artística, religiosa entre os indivíduos de uma determinada época. Podemos enfatizar, com Lukács, que o espírito moderno, por exemplo, comporta o princípio da subjetividade ou que o "espírito grego" é determinado pelo princípio artístico da beleza. "Totalidade do ser só é possível quando tudo já é homogêneo", afirma o autor da Teoria do romance, "antes de ser envolvido pelas formas; [...] quando saber é virtude e a virtude, felicidade; quando a beleza póe em evidência o sentido do mundo." (LUKÁCS, 2000, p. 31, grifo nosso).

Parece ser esse o critério adotado por Lukács para compreender a unidade de sentido dada no conceito de espírito, ou seja, há um sentido universal que concentra em si todas as particularidades individuais num momento histórico particular. Esse sentido, sendo imanente à própria realidade histórica apenas do ponto de vista particular ou individual, pode ser reconstituído racionalmente somente com base em um construto artificial, o qual possibilita ao ensaísta transitar da particularidade ao universal, seja do indivíduo ao todo, da obra ao gênero, seja ainda da época à história, estabelecendo as suas conexóes. Nesse sentido, se podemos sustentar que o jovem Lukács articula a história a partir de um critério racional - afinal, toda teoria pretende explicar 
as múltiplas experiências individuais sob a perspectiva de um critério universal - esse critério difere do critério especulativo hegeliano, pois, onde este último apresenta, em razão de a objetividade ser apreendida como desdobramento da subjetividade, uma relação de imanência, o autor húngaro pensa, ao contrário, em função de uma separação semelhante ao corte transcendental entre a forma e o conteúdo.

O procedimento especulativo, assim como a própria modernidade que lhe fornece a substância histórica, aparece aos olhos de Lukács como uma objetivação abstrata e formal do sujeito. A parte - a alma ou o indivíduo - é entendida de modo substancial, porque possui algo de verdadeiro, ainda que unilateral, da totalidade, do todo. Na efetividade da experiência moderna, o todo é apresentado na figura do Estado, que suspende as partes. Se o todo do Estado é a verdade da Filosofia do direito de Hegel, "o falso consiste em transformar esse todo em alma” (LUKÁCS apud MACHADO, 2004, p. 65), escreve Lukács, na carta para o amigo Ernst. O que aparece como "falso", assim, junto com o Estado e a objetividade do mundo social, é a própria unidade filosófica indicada por Hegel, a totalidade reconciliada, pois, antes de apresentar uma unidade real das múltiplas experiências do indivíduo isolado da sociedade civil burguesa, este parece fornecer apenas formalmente essa unidade, a qual Hegel encontra no Estado que suspende e unifica os mais variados interesses individuais na cidadania, no interesse coletivo do Estado.

A crítica da unidade conceitual da filosofia hegeliana, isto é, a não aceitação por Lukács de uma dialética que unifica e expóe a totalidade, pode ser aproximada, dessa maneira, à sua crítica à resposta formal do romance ao problema da cisão moderna entre vida e sentido.

O romance instaura o "indivíduo problemático" moderno, todavia, esse indivíduo é configurado no interior de uma totalidade criada, artificial. A proposta formal do romance é, assim, a da criação do sentido, não na vida, mas sob o domínio da forma literária. É por isso que, no decorrer da exposição da Teoria do romance, a saída encontrada pelos românticos - uma saída situada apenas na forma artística para a ausência de sentido - aparece somente como uma resposta formal. A totalidade é criada, seja a partir de um recorte da realidade, seja pela configuração de um mundo ideal, separado da realidade, aqui compreendida em sua correlação com a empiria da vida. Impossibilitado de configurar a vida em sua totalidade, o romântico tem que destacar um aspecto da realidade, assim como acolher a cisão entre homem e mundo, porque, 
de outra forma, qualquer tentativa de criar um mundo utópico destacado da “empiria da vida está fadado ao fracasso." (LUKÁCS, 2000, p. 44).

O romance corre sempre o perigo de dissolver a forma ou transmutarse em outras formas, porque está numa constante problemática: ele deve acolher, em sua configuração, a fragmentaçãa do momento histórico-filosófico moderno, além de dever configurar uma totalidade artística, no entanto, tal totalidade criada - pois não se apresenta na própria efetividade - é o perigo da forma romance, na medida em que a matéria configurada pode atingir o auge da abstração e, desse modo, não ter nenhuma unidade com o momento histórico. Essa abstração está dada, por exemplo, na contraposição romântica de uma totalidade utopicamente criada em face da própria realidade existente. Afirma Lukács, em relação ao perigo da abstração para a forma romance, que, em qualquer saída romântica que contraponha uma "profissão de fé de toda composição literária” (LUKÁCS, 2000, p. 87) à realidade, a luta está fadada a ter impreterivelmente um vencedor: a realidade. ${ }^{3}$

Nesse sentido determinado, a recusa por Lukács à identidade encontrada por Hegel na forma do Estado moderno e do conceito - que, para o autor húngaro, não corresponde à experiência histórica moderna, não possuindo assim qualquer valor substancial - significa que a filosofia hegeliana apresenta uma saída igualmente formal, porque corresponde a uma suspensão filosófica de uma realidade fundamentalmente determinada e dominada, conforme a sua leitura, não pela unidade ou totalidade na vida, mas pela cisão, pela luta de todos contra todos da sociedade civil burguesa, da qual a substanciação do Estado não é senão uma abstração formal.

A suprassunção (Aufhebung) da esfera da sociedade civil burguesa pelo Estado não significa, para Hegel, uma dissolução daquela esfera, porém, uma suspensão que conserva em seu interior o momento da subjetividade. $\mathrm{O}$ indivíduo burguês, na luta pelo seu interesse, é alçado ao posto de cidadão do Estado, mediado pelas corporaçóes, que assim suprassume o caráter fragmentário ou cindido de sua existência, na esfera da sociedade civil burguesa, isto é, segundo a leitura de Hegel, ao experimentar-se como cidadão, o homem da sociedade civil efetivamente é levado a suprassumir (alfheben) o seu ponto de vista subjetivo e privado, à medida que, como cidadão, deve considerar não mais o interesse da parte, mas o do todo. O Estado é, por conseguinte,

${ }^{3}$ A crítica ao romantismo permeia toda a Teoria do romance. Nesse ponto específico, ele critica a posição romântica de a crítica do presente estar fundamentada a partir de uma evasão do próprio presente. 
compreendido como a instância superior que incorpora e distribui a produção alicerçada naqueles interesses particulares para a coletividade, realizando o interesse do todo.

A hipótese com a qual trabalhamos é de que essa discussão acerca da unidade hegeliana encerrada no conceito de espírito, se confrontada com a posição de Lukács, é inseparável da problemática da relação entre "ética de esquerda e epistemologia de direita" (LUKÁCS, 2000, p. 17), tematizada por Lukács no Prefácio de 1962. Se a unidade ou o todo só é possível a partir da "função sintética" e não na realidade, a separação entre forma e conteúdo, aquela que Lukács chamará na maturidade de "epistemologia de direita”, em razão de sua inspiração nas ciências do espírito, serve aqui a uma ética de esquerda, que visa a garantir a separação do autor da Teoria do romance em relação ao juízo hegeliano sobre o Estado moderno como realização da unidade, como um todo reconciliado. Essa crítica do jovem Lukács ao idealismo hegeliano - em razão de seu realismo, de sua adesão à conformidade do Estado moderno à racionalidade - se encontra ainda situada numa perspectiva também idealista.

A Teoria do romance não estabelece a "marcha do espírito" em termos de um desenvolvimento necessário, uma vez que, não se trata de "aventar [...] uma filosofia da história” (LUKÁCS, 2000, p. 34), seja como avanço, seja como regresso, pois o que ela critica é o caráter mediador da objetividade, a qual, em Hegel, é idêntica ao Estado, por meio do qual a parte pode também ser entendida em sua identidade com o todo e pela qual, ao olhar a partir do Estado moderno para o passado, a marcha da história aparece em sua necessidade. Em Hegel, é essa mediação objetiva que torna possível apresentar a "marcha do espírito" ou a história, concebida como desenvolvimento racional e necessário. $\mathrm{Na}$ mescla muito peculiar de influências metodológicas, Lukács visa a interromper o fluxo (ou a "marcha") que, em Hegel, articula o desenvolvimento particular do espírito do povo ao espírito universal. Ao mesmo tempo, ele se aproxima do espírito hegeliano, ao apresentar a forma em unidade com a vida ou a forma em íntima conexão com o conteúdo. Como a sua aproximação critica a mediação pela objetividade no Estado, ele permanece asseverando essa relação entre forma e conteúdo apenas de um ponto de vista subjetivo ou formal.

Isso significa que, para Lukács, é pela unidade dada na alma, concebida como subjetividade, que as conexôes entre alma e mundo podem se apresentar. Isso é talvez o que explica o porquê de o autor da Teoria do romance 
persistir na forma literária como forma capaz de expor o sentido, quando, ao contrário, para Hegel, apenas a filosofia pode, na modernidade, fazê-lo. De acordo com a conclusão da Estética, a arte na modernidade somente pode configurar o sentido de um ponto de vista subjetivo, o que situa, sob esse ponto de vista, a posição de Lukács como próxima à postura romântica. A influência da epistemologia weberiana - o formalismo da unidade - parece apontar o lugar da Teoria do romance em sua proximidade ao idealismo do romantismo, visto que a unidade com o todo é possível apenas formalmente, mas não na vida. Essa afirmação deve ser, todavia, nuançada. Por outro lado, se essa epistemologia aproxima o autor de uma saída apenas formal, não é possível esquecer que, de alguma maneira, essa saída ainda formal é nomeadamente contraposta por ele ao formalismo romântico, seja do romantismo da desilusão, seja da saída configurada por Tolstói, de uma "forma renovada da epopeia".

Há um idealismo acentuado nas páginas da Teoria do romance, por exemplo, ao considerar que a condição para a compreensão do novo mundo seria uma "exegese histórico-filosófica" da obra de Dostoiévski (LUKÁCS, 2000, p. 161). Quando Lukács, em contrapartida, apresenta a pergunta se o "novo mundo" configurado por Dostoiévski já apontaria para uma nova experiência social - experiência não mais romântica -, é a superação da cisão que esse "novo mundo" representaria o que resgata na própria vida o sentido que, no romance, aparece de modo formal. Afinal, a obra de Dostoiévski apenas pode ser entendida como expressão de um "novo mundo" se, como na epopeia homérica, ela apresentar uma relação de imanência entre sentido e vida (LUKÁCS, 2000, p. 259-260). Isso parece expressar com clareza a contradição sob a qual se move a Teoria do romance: de um lado, é a análise formal que deve ajuizar sobre o novo mundo; de outro lado, para Lukács, não se trata apenas ou primordialmente da obra literária, contudo, de averiguar se a obra de Dostoiévski é já a expressão de novas relações de sentido, se ela é a exposição da construção de uma nova experiência com o sentido ou de um novo mundo, que assim a obra apenas expóe, como ocorre na epopeia homérica.

SILVA FILHO, A. V. Hegel's philosophy in the light of Lukács The theory of the novel. Trans/form/ação, Marília, v. 41, n. 4, p. 75-90, Out./Dez., 2018. 
ABSTRACT: This article discusses the inheritance of the Hegelian historical dialectic present in the young Lukács The theory of the novel, and the distancing of the Hungarian author from Hegel's conclusions about the effective unity between the individual and modern state. The Hegelian heritage is definitive in Lukács understanding of the immanent and necessary relationship between artistic form and historical content. For Hegel, modernity and state institutions appear as the highest indicators of human freedom in history, whereas for Lukács, on the contrary, modernity is presented as the culmination of alienation between the individual and social structures, an alienating process which begins when the world of the epic is supplanted by the Greek nation-state of tragedy and philosophy.

KeYworDs: Theory of the Novel. Lukács. Spirit. State. Hegel.

\section{REFERÊNCIAS}

ARATO, A.; BREINES, P. El jovem Lukács y los orígenes del marxismo occidental. Novo México: Fóndo de Cultura Económica, 1986.

HEGEL, G. W. F. Lecciones sobre la filosofia de la historia universal. Tradução de José Gaos. Madrid: Alianza, 1989.

. Linhas fundamentais da filosofia do direito. Terceira parte: eticidade; Terceira seçáo: O Estado. Tradução de Marcos Lutz Müller. Campinas: IFCH/UNICAMP, 1998.

. Linhas fundamentais da filosofia do direito: a sociedade civil. Tradução de Marcos Lutz Müller. Campinas: IFCH/UNICAMP, 2000.

- Cursos de estética. Tradução de Marco Aurélio Werle e Oliver Tolle. São Paulo: Editora da Universidade de São Paulo, 2004. V. 4.

LUKÁCS, G. A teoria do romance: um ensaio histórico-filosófico sobre as formas da grande épica. Tradução, posfácio e notas de José Marcos Mariani de Macedo. São Paulo: Duas Cidades; Ed. 34, 2000.

MACHADO, C E. J. As formas e a vida: estética e ética no jovem Lukács (1910-1918). São Paulo: Editora UNESP, 2004.

WEBER, M. A "objetividade” do conhecimento nas ciências sociais. In: COHN, G. (Org.). Sociologia. São Paulo: Ática, 1997. p. 79-127.

Recebido: 01/11/2016

Aceito: 20/10/2017 